MENEZES JÚNIOR, F.O.G.; FERNANDES, H.S.; MAUCH, C.R.; SILVA, J.B. Caracterização de diferentes substratos e seu desempenho na produção de mudas de alface em ambiente protegido. Horticultura Brasileira, Brasília, v. 18, n. 3, p. 164-170, novembro 2.000.

\title{
Caracterização de diferentes substratos e seu desempenho na produção de mudas de alface em ambiente protegido. ${ }^{1}$
}

\author{
Francisco Olmar G. Menezes Júnior ²; Heloísa S. Fernandes ²; Carlos Rogério Mauch ²; João Baptista da \\ Silva ${ }^{3}$ \\ ${ }^{2}$ UFPel - Dep ${ }^{\text {to }}$ de Fitotecnia; ${ }^{3}$ UFPel - IFM, C. Postal 354, 96.010-900 Pelotas - RS. e.mail: fgervini@zaz.com.br
}

\begin{abstract}
RESUMO
Considerando a necessidade de substratos para a produção de mudas de alface e a existência de diversos substratos comerciais e indicações para a formulação destes, foram avaliados nove substratos hortícolas para produção de mudas de alface sob estufa plástica. Os tratamentos consistiram de três testemunhas, sendo dois substratos comerciais (Plantmax e Planta Forte) e um recomendado pelo órgão oficial de assistência técnica (EMATER-RS), comparados a seis formulados a partir de solo podzólico vermelho amarelo (S) ou turfa "Petrolini" (T) misturados em três proporções em base de volume $(1: 3,1: 1,3: 1)$ de vermicomposto (V). Avaliaram-se as propriedades físicas, químicas e físico-química dos tratamentos, respostas biológicas das mudas, assim como a viabilidade técnica e econômica da produção de alguns substratos na propriedade agrícola. Segundo estes critérios, as melhores respostas foram obtidas para os substratos $\mathrm{S}_{75} \mathrm{~V}_{25}, \mathrm{~S}_{50} \mathrm{~V}_{50}$ e $\mathrm{S}_{25} \mathrm{~V}_{75}$, os quais apresentaram maiores vantagens comparativas em relação às testemunhas e demais substratos. $\mathrm{O}$ bom desempenho alcançado pelos substratos formulados, indica ser sua produção, na propriedade, uma alternativa técnicamente viável em substituição ao uso de substratos comerciais.
\end{abstract}

Palavras-chave: Lactuca sativa, meios de cultivo, vermicomposto, viabilidade técnica e econômica.

\begin{abstract}
Characterization and performance of different substrates for lettuce plug-type transplants production under protected environment.

The purpose of this work was to evaluate nine substrates for lettuce plug-type transplants production under plastic greenhouse. Two commercial substrates (Plantmax and Planta Forte) and one mixture recommended by the extension service (EMATER-RS) were compared with six formulated mixtures from "red-yellow podzolic soil" (S) or peat "Petrolini" (T) mixed in three different proportions on a volume/volume bases $(1: 3,1: 1,3: 1)$, with an earthworm compost $(\mathrm{V})$. The physical and chemical proprieties of each treatment and the biological response were evaluated, as well as the technical and economical feasibility of producing these substrates in the farm. Best responses were obtained with $\mathrm{S}_{75} \mathrm{~V}_{25}, \mathrm{~S}_{50} \mathrm{~V}_{50}$ e $\mathrm{S}_{25} \mathrm{~V}_{75}$ mixtures. These substrates can substitute with advantage the two commercial substrates and the mixture recommended by extension service.
\end{abstract}

Keywords: Lactuca sativa, earthworm compost, technical and economical feasibility.

\section{(Aceito para publicação em 10 de agosto de 2.000)}

\begin{abstract}
$\mathrm{A}$ produção de mudas de hortaliças constitui-se numa das etapas mais importantes do sistema produtivo (Silva Júnior et al., 1995), uma vez que dela depende o desempenho final das plantas nos canteiros de produção, tanto do ponto de vista nutricional, quanto do tempo necessário para a produção e, conseqüentemente, do número de ciclos produtivos possíveis por ano (Carmello, 1995). Os recentes avanços dos sistemas de produção empregados, têm proporcionado aumentos substanciais de produção e produtividade, os quais se devem, em grande parte, à substituição do uso do solo mineral como meio de cultivo por substratos artificiais (De Boodt, 1974). Devido a isso, o franco
\end{abstract}

desenvolvimento da atividade de produção e comercialização especializada de mudas de hortaliças, tem-se baseado, principalmente, na pesquisa de melhores fontes e combinações de substratos (Giorgetti, 1991).

O substrato hortícola pode ser conceituado como o meio onde se desenvolvem as raízes das plantas produzidas em sementeiras e/ou viveiros de mudas olerícolas, ornamentais, frutíferas ou silvícolas (Bellé, 1990; Carneiro, 1995). Diferem dos solos, por terem sido removidos dos seus locais de origem e serem produzidos artificialmente (Verdonck et al., 1981). Enquanto o solo possui valores fixos quanto ao seu potencial produtivo, os substratos, quan- do bem formulados, permitem melhores condições ao desenvolvimento vegetal especialmente em cultivos protegidos, os quais exigem um ambiente radicular "refinado" (Penningsfeld, 1978).

O problema agronômico original da produção de mudas em recipientes é o de assegurar o crescimento e produção de biomassa aérea com volume limitado de raízes, restritas a um pequeno volume de substrato (Mele et al., 1982; Sancho, 1988; Lamaire, 1995). Assim, quanto menor for o espaço disponível às raízes, mais difícil será o suprimento de fatores ótimos de produção que garantam o crescimento e desenvolvimento normal da muda (Jungk, 1975). Portanto, o substrato desempenha importan-

\footnotetext{
${ }^{1}$ Parte do trabalho de dissertação de mestrado em Agronomia, área de concentração em Produção Vegetal, pela Faculdade de Agronomia "Eliseu Maciel"- UFPel - Campus do Capão do Leão - RS.
} 
te papel, ou seja, o de garantir por meio de sua fase sólida a manutenção mecânica do sistema radicular e estabilidade da planta, da fase líquida o suprimento de água e nutrientes e da fase gasosa o suprimento de oxigênio e o transporte de dióxido de carbono entre as raízes e o ar externo (Lamaire, 1995). Deve ainda estar isento de elementos minerais ou qualquer outras substâncias em concentrações fitotóxicas, assim como de fitopatógenos, pragas e plantas indesejáveis (Carneiro, 1995; Minami, 1995).

As propriedades físicas dos substratos são consideradas de grande importância, uma vez que as relações ar:água não podem ser mudadas durante o cultivo (Verdonck, 1983). Destacam-se, entre elas, a densidade, a porosidade total, o espaço de aeração e a capacidade de retenção de água (água disponível, água facilmente disponível e água de reserva). Um bom substrato deve reunir concomitantemente os atributos de boa aeração, para permitir a difusão de oxigênio para as raízes, boa capacidade de armazenamento de água, baixa resistência à penetração das raízes e boa resistência à perda de estrutura (Silva Júnior \& Visconti, 1991; Souza et al., 1995). Deve ainda, segundo Tessarioli Neto, 1995, citado por Minami (1995), apresentar baixa densidade, isenção de contaminações fitopatogênicas e baixo custo.

Em relação às propriedades químicas, o teor total de sais solúveis, o $\mathrm{pH}$ e a capacidade de troca de cátions (CTC) merecem atenção especial. $\mathrm{O}$ uso de substratos excessivamente ricos em nutrientes não é recomendado, uma vez que os sais solúveis podem prejudicar o crescimento das plantas (Graziano et al., 1995), enquanto que valores inadequados de $\mathrm{pH}$, além de influenciar a disponibilidade de nutrientes (Carneiro, 1995), estão relacionados a muitos desequilíbrios fisiológicos (Waller \& Wilson, 1983). A capacidade de troca de cátions (CTC), por sua vez, é uma valiosa informação do potencial de fertilidade de um substrato. Como muitos cátions existentes no substrato são nutrientes, a CTC expressa a potencialidade de armazenamento e fornecimento desses nutrientes às plantas (Kiehl, 1979, Carneiro, 1995).
Entre as propriedades químicas destaca-se o teor de matéria orgânica. A matéria orgânica atua nos substratos melhorando diversas propriedades físicas e químicas. Os principais benefícios proporcionados pela sua adição em substratos são: aumento da capacidade de retenção de água, da porosidade total e do espaço de aeração e diminuição da densidade, além de servir como fonte e reservatório de nutrientes (Bellé, 1990, Carneiro, 1995).

Mesmo com o reconhecimento da importância do substrato no sistema de produção de mudas, a maior parte das pesquisas, tanto de caracterização, quanto de desempenho dos meios de cultivo têm sido voltadas ao desenvolvimento de substratos para produção de mudas de plantas ornamentais, frutíferas e silvícolas, sendo escassas em relação às diferentes espécies oleráceas (Menezes Júnior, 1998).

Por outro lado, estão disponíveis no mercado nacional diferentes substratos comerciais, recomendados indistintamente para diferentes espécies, cujas formulações e propriedades são praticamente desconhecidas e, cujos desempenhos como meio de cultivo ainda não estão bem estabelecidos.

Em virtude das escassas informações sobre os substratos para a produção de mudas de alface, objetivou-se neste trabalho a caracterização física e química de dois substratos comerciais (Plantmax e Planta Forte), de uma mistura recomendada pela EMATER - RS e de seis substratos formulados a partir de "solo podzólico vermelho amarelo" ou turfa "Petrolini", misturados em diferentes proporções com vermicomposto de esterco bovino (material proveniente da vermicompostagem do esterco bovino pela minhoca Eiseinia foetida). Avaliouse o desempenho e a viabilidade técnica e econômica dos diferentes substratos para a produção de mudas de alface.

\section{MATERIAL E MÉTODOS}

O presente estudo foi desenvolvido em laboratório do Departamento de Solos e, em estufa no Campo Experimental do Departamento de Fitotecnia da Faculdade de Agronomia "Eliseu Maciel" da Universidade Federal de Pelotas, lo- calizados a uma latitude de $31^{\circ} 52^{\prime} 00^{\prime} \mathrm{S}$, longitude de $52^{\circ} 21^{\prime} 24^{\prime}$ 'W e altitude 13 $\mathrm{m}$, durante o período de 03/05/97 a 05/ 06/97. O clima local é classificado, segundo Köppen, em Cfa, ou seja, clima temperado $(\mathrm{C})$, com chuvas bem distribuídas (f) e verões suaves (a).

A estufa plástica utilizada foi a modelo arco abatido com 10,5 m de comprimento, 4 metros de largura e $2,5 \mathrm{~m}$ de altura, disposta no sentido norte-sul, com estrutura de madeira e cobertura de filme de polietileno de baixa densidade (PEBD), com aditivo ultravioleta e espessura de $100 \mathrm{~m}$. As laterais da mesma eram móveis, permitindo o total manuseio para a abertura ou fechamento. A estufa foi mantida completamente fechada durante a noite (das 18 às 8 horas) e aberta, lateralmente, durante o dia (das 8 às 18 horas).

Foram utilizadas bandejas de poliestireno expandido de 288 células e volume de $9,70 \mathrm{~cm}^{3}$, sustentadas por bancadas a uma altura de 1 metro em relação à superfície do solo, as quais permitiram o perfeito nivelamento das bandejas, objetivando-se garantir o uniforme suprimento de água às plântulas.

O sistema de irrigação foi composto por uma bomba de $3 / 4$ de c.v. e uma linha central com 8 microaspersores com sistema antigotejo, distanciados uns dos outros em $2 \mathrm{~m}$, raio de ação de 2,5 m e, a uma altura de 1,0 $\mathrm{m}$ das bandejas. Procedeu-se à irrigação diária das plântulas e mudas, durante o período de 3 minutos, duas a três vezes ao dia, dependendo das condições meteorológicas locais.

No interior da estufa plástica, foram registradas ao longo do experimento, a temperatura e umidade relativa médias, de $20,1^{\circ} \mathrm{C}$ e $75,7 \%$, respectivamente, em termohigrógrafo da marca Wilh Lambrecht, de registro semanal, instalado a 1,5 $\mathrm{m}$ do solo, no interior de um abrigo meteorológico, localizado na extremidade sul da estufa.

Dois comerciais (Plantmax e Planta Forte) e um substrato recomendado por extensionistas do Capão do Leão, RS (denominado EMATER, e composto de solo, turfa "Petrolini" e casca de arroz carbonizada, na proporção, em volume, de 1:1:1) foram comparados com outras seis formulações. As seis combinações foram misturas de solo (S) ou turfa 
Tabela 1. Tempo de emergência e número de folhas definitivas de mudas de alface obtidas por contagem (valores não transformados) e, peso de matéria seca da parte aérea (PMSPA), do sistema radicular (PMSSR), e total (PMST) das mudas de alface. Pelotas, UFPel, 1998.

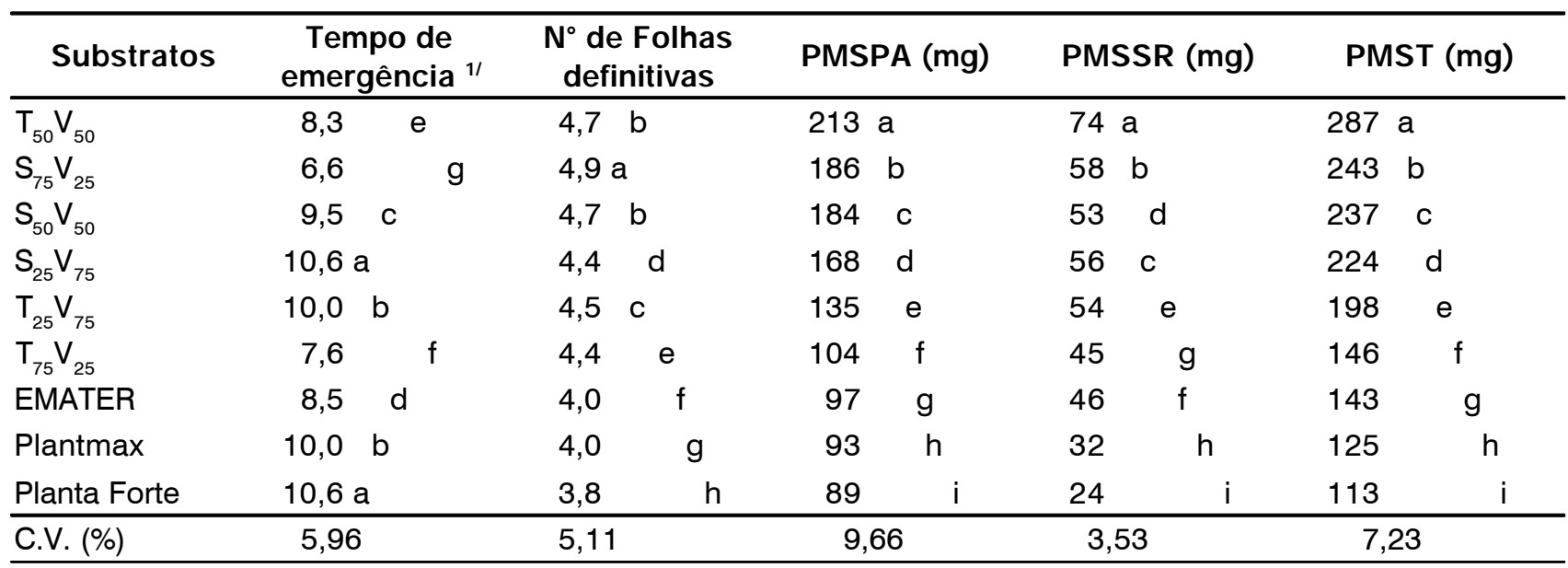

*/ Médias seguidas da mesma letra nas colunas não diferem entre si a 5\% de probabilidade pelo teste de Duncan;

1/ Dias após a semeadura.

"Petrolini" (T) com vermicomposto (V), nas proporções de 25,50 e $75 \%$ em volume, obtendo-se os seguintes substratos: $\mathrm{T}_{75} \mathrm{~V}_{25}, \mathrm{~T}_{50} \mathrm{~V}_{50}, \mathrm{~T}_{25} \mathrm{~V}_{75}, \mathrm{~S}_{75} \mathrm{~V}_{25}$, $\mathrm{S}_{50} \mathrm{~V}_{50}$ e $\mathrm{S}_{25} \mathrm{~V}_{75}$. Como solo utilizou-se a camada de 0 a $20 \mathrm{~cm}$ de um Podzólico Vermelho Amarelo de classe textural franca arenosa. A turfa, encontrada em adiantado estado de decomposição (turfa preta), foi extraída na Estação Experimental Domingos Petrolini, coletandose a camada de 10 a $50 \mathrm{~cm}$ de profundidade, corrigindo-se a acidez para $\mathrm{pH}$ 6,0 por meio de calcário dolomítico. $\mathrm{O}$ vermicomposto ou húmus de minhoca foi obtido junto ao comércio local, sendo proveniente da vermicompostagem de esterco bovino, por meio da minhoca vermelha-da-califórnia - Eiseinia foetida. A exceção da casca de arroz carbonizada, os demais materiais foram peneirados em duas peneiras, com abertura de malhas de $20 \mathrm{~mm}$ e $4 \mathrm{~mm}$, respectivamente, e, desinfestados com brometo de metila na dosagem de 150 $\mathrm{cm}^{3} \cdot \mathrm{m}^{-3}$.

Os substratos formulados, com exceção dos comerciais, receberam uma adubação de base de 2 g. $\mathrm{L}^{-1}$, da fórmula 520-10, indicada por técnicos da EMATER do Capão do Leão, RS. Utilizou-se o delineamento blocos casualisados com três repetições, sendo cada parcela constituída de 96 plantas.

A cultura utilizada no experimento foi a alface, cultivar Monalisa, semeada em $03 / 05 / 97$, na profundidade de $5 \mathrm{~mm}$, colocando-se duas sementes no centro de cada célula da bandeja. $\mathrm{O}$ desbaste foi realizado em 12/05/97, quando as plantas apresentaram a primeira folha definitiva desenvolvida, deixando-se uma plântula por célula.

Foram avaliadas as seguintes propriedades físicas e químicas dos diferentes tratamentos: densidade de volume seco (DS); pH; e o teor total de sais solúveis (TTSS), calculados conforme os métodos utilizados pela União das Entidades Alemãs de Pesquisas Agrícolas (VDLUFA) e descritos por Hoffmann (1970); distribuição do tamanho de partículas (DTP), segundo Prasad (1979a, 1979b) e Bilderback et al. (1982); porosidade total (PT), espaço de aeração (EA), água disponível (AD), água facilmente disponível (AFD) e água de reserva (AR), a partir da metodologia proposta por De Boodt \& Verdonck (1972) modificada por Menezes Júnior (1998), Prasad (1979a, 1979b), Bilderback etal. (1982) e; teor de matéria orgânica (MO) por meio da combustão de amostras em forno mufla à temperatura de $550^{\circ} \mathrm{C} \mathrm{du}$ rante o período de cinco horas (Kiehl, 1979); capacidade de troca de cátions (CTC), segundo a metodologia proposta por Tedesco et al. (1985).

Para as avaliações biológicas obteve-se o tempo de emergência (TE emergência de $50 \%$ das plantas da parcela), pela contagem diária; pesos de matéria seca da parte aérea (PMSSA), do sistema radicular (PMSSR) e peso total
(PMST); e o número de folhas definitivas avaliados 34 dias após a data de semeadura, por ocasião da coleta das mudas. Os dados obtidos foram submetidos à análise de variância e as médias comparadas pelo teste de Duncan ao nível de $5 \%$ de probabilidade.

Os dados de custo dos substratos foram obtidos considerando o custo da produção do vermicomposto, junto à Cooperativa de Minhocultores da Região Sul e o custo de desinfestação dos materiais puros com brometo de metila, na dosagem de $50 \mathrm{~cm}^{3} \cdot \mathrm{m}^{-3}$. Esses dados foram comparados ao preço dos substratos comerciais praticados no comércio local.

\section{RESULTADOS E DISCUSSÃO}

A emergência das plântulas de alface ocorreu entre 6,6 e 10,6 dias, conforme os diferentes tratamentos (Tabela 1). Nas doses mais elevadas de vermicomposto, assim como nos substratos comerciais foi verificado o maior tempo de emergência das plântulas, enquanto na mais baixa concentração de vermicomposto $(25 \% \mathrm{em}$ volume) esta ocorreu aos 6,6 e 7,6 dias após a semeadura, ou seja, para os substratos $\mathrm{S}_{75} \mathrm{~V}_{25}$ e $\mathrm{T}_{75} \mathrm{~V}_{25}$, respectivamente. $\mathrm{O}$ alto conteúdo de sais encontrado no vermicomposto e nos substratos comerciais poderá ter afetado drasticamente a germinação das sementes (Ta- 
Tabela 2. Valores de pH (em água), teor total de sais solúveis (TTSS), capacidade de troca de cátions (CTC) e matéria orgânica (MO) dos materiais puros, substratos comerciais e formulados em estudo de formação de mudas de alface. Pelotas, UFPel, 1998.

\begin{tabular}{|c|c|c|c|c|c|c|c|c|}
\hline Materiais puros & \multicolumn{2}{|c|}{$\mathrm{Ph}\left(\mathrm{H}_{2} \mathrm{O}\right)$} & \multicolumn{2}{|c|}{ TTSS $\left(g . L^{-1}\right)$} & \multicolumn{2}{|c|}{ CTC $\left(\mathrm{mmol}_{\mathrm{c}} \mathrm{dm}^{-3}\right)$} & \multicolumn{2}{|c|}{ MO (dag. kg $\left.^{-1}\right)$} \\
\hline Turfa $(T)^{1 /}$ & 4,40 & & 0,38 & & 73,9 & & 8,01 & \\
\hline Solo (S) $)^{21}$ & 5,69 & & 0,39 & & 79,3 & & 4,33 & \\
\hline Casca $(C)^{3 /}$ & 7,92 & & 4,11 & & 41,1 & & 10,57 & \\
\hline $\begin{array}{l}\text { Vermicomposto }(\mathrm{V})^{4 /} \\
\text { Substratos }\end{array}$ & 6,21 & & 6,18 & & 175,2 & & 16,72 & \\
\hline Plantmax & 5,07 & $\mathrm{i}$ & 6,17 & b & 132,8 & $f$ & 14,75 & c \\
\hline Planta Forte & $7,00 \mathrm{a}$ & & 5,62 & c & 193,7 & b & $15,60 \mathrm{a}$ & \\
\hline EMATER & 5,70 & $\mathrm{~h}$ & 1,48 & $\mathrm{i}$ & 67,9 & $\mathrm{i}$ & 8,88 & $\mathrm{~h}$ \\
\hline $\mathrm{T}_{75} \mathrm{~V}_{25}$ & 5,71 & $\mathrm{~g}$ & 2,72 & $\mathrm{~h}$ & 124,1 & $\mathrm{~h}$ & 10,05 & $g$ \\
\hline $\mathrm{T}_{50} \mathrm{~V}_{50}$ & 5,94 & $\mathrm{e}$ & 4,49 & e & 154,2 & e & 12,62 & e \\
\hline $\mathrm{T}_{25} \mathrm{~V}_{75}$ & 6,04 & $c$ & $6,19 a$ & & 216,9 & & 15,50 & b \\
\hline $\mathrm{S}_{75} \mathrm{~V}_{25}$ & 5,79 & $f$ & 2,97 & g & 126,3 & g & 7,73 & $\mathrm{i}$ \\
\hline $\mathrm{S}_{50} \mathrm{~V}_{50}$ & 6,00 & $d$ & 3,57 & $f$ & 155,5 & d & 11,08 & f \\
\hline $\mathrm{S}_{25} \mathrm{~V}_{75}$ & 6,18 & $\mathrm{~b}$ & 4,96 & d & 179,2 & $\mathrm{C}$ & 12,80 & d \\
\hline C.V. (\%) & 1,49 & & 8,29 & & 1,03 & & 20,26 & \\
\hline
\end{tabular}

*/ Médias seguidas da mesma letra nas colunas não diferem entre si a 5\% de probabilidade pelo teste de Duncan;

1/ Turfa "Petrolini"; ${ }^{2 /}$ solo PVA; 3 / casca de arroz carbonizada; $4 /$ vermicomposto.

bela 2). Segundo Backes et al. (1988), um alto teor de sais solúveis pode provocar a queima ou necrose das raízes, sendo resultante de condições inerentes do próprio substrato ou excesso de adubação. De acordo com Penningsfeld (1983), o teor máximo de sais permitido para espécies tolerantes é de 3 g.L. $\mathrm{L}^{-1}$. Assim, pode-se concluir que apenas os substratos $\mathrm{S}_{75} \mathrm{~V}_{25}, \mathrm{~T}_{75} \mathrm{~V}_{25}$ e EMATER não apresentaram níveis excessivos de sais, havendo nas misturas preparadas um efeito de diluição, o qual traduziu-se na maior rapidez de emergência das mudas. Embora para o substrato $\mathrm{T}_{50} \mathrm{~V}_{50}$ tenha sido registrado um alto teor de sais solúveis totais e um menor tempo de emergência em relação a outros, tal fato deve-se à dificuldade de serem obtidas amostras representativas quando ao meio são adicionadas pequenas quantidades de adubo na forma granulada, o que pode mascarar a quantidade real de sais presentes no pequeno volume ocupado pelo substrato (células das bandejas). Segundo Menezes Júnior (1998), deve-se dar preferência à adubação foliar, uma vez que a utilização de adubos granulados em substratos não garante uma boa uniformidade de distribuição destes nas células das bandejas, o que pode acarretar tanto deficiências nutricionais como problemas de salinidade e/ou fitotoxicidade.

A alta porosidade total dos substratos Plantmax, Planta Forte, $\mathrm{T}_{50} \mathrm{~V}_{50}, \mathrm{~S}_{50} \mathrm{~V}_{50}, \mathrm{~T}_{25} \mathrm{~V}_{75}$ e $\mathrm{S}_{25} \mathrm{~V}_{75}$ (Tabela $3)$, possivelmente permitiu, por ocasião das primeiras irrigações, a lixiviação do excesso de sais, propiciando, embora tardiamente, a germinação. Dos substratos testados, a mais rápida emergência foi observada para aquele formulado com $75 \%$ de "solo" e $25 \%$ de vermicomposto (S75V25) em volume (Tabela 1).

Em relação ao desenvolvimento das plântulas, observou-se que o substrato que proporcionou o menor tempo de emergência produziu mudas com maior número de folhas e maior quantidade de matéria seca (Tabela 1). A adição de vermicomposto em $25 \%$ e $75 \%$ em volume no substrato formulado com turfa "Petrolini", reduziu o desenvolvimento das plântulas. No primeiro caso, o baixo espaço de aeração $(7,45 \%$ em volume), proporcionado pela predominância de partículas menores entre 0,250 e $0,106 \mathrm{~mm}(64,6 \%$ em volume), prejudicou o desenvolvimento radicular, provavelmente, por dificultar a difusão de oxigênio às raízes (Tabelas 3 e 4). Tal fato traduziu-se em menor peso de ma- téria seca do sistema radicular, o qual não foi suficiente para garantir um bom desenvolvimento do sistema aéreo, sendo observados menor número de folhas definitivas e pesos de matéria seca aérea e total (Tabela 1). Estes dados concordam com Handreck (1983), Bordas et al. (1988) e Souza et al. (1995), os quais relatam a influência do espaço de aeração de partículas compreendidas na faixa anteriormente citada, além da necessidade dos substratos possuírem um espaço de aeração entre 10 e $20 \%$ e os efeitos prejudiciais advindos de valores abaixo dos recomendados. No segundo caso, o alto teor total de sais solúveis, aliado a uma baixa relação entre este e os teores de água disponível e água facilmente disponível, determinaram o atraso na emergência das plântulas, assim como no desenvolvimento vegetativo destas (Tabelas 2 e 3). Estes dados estão de acordo com Silva Júnior et al. (1995), os quais citam que a concentração salina interfere no processo osmótico, que por sua vez é controlado pela relação concentração salina:teor de água no solo (ou substrato). Segundo Malavolta (1981), uma alta concentração de sais solúveis na solução do solo, em contato com uma planta jovem podem causar a perda de água pelas raízes, 
Tabela 3. Densidade seca (DS), porosidade total (PT), espaço de aeração (EA), água disponível (AD), água facilmente disponível (AFD) e água de reserva (AR) dos materiais puros e tratamentos de substrato para a formação de mudas de alface. Pelotas, UFPel, 1998.

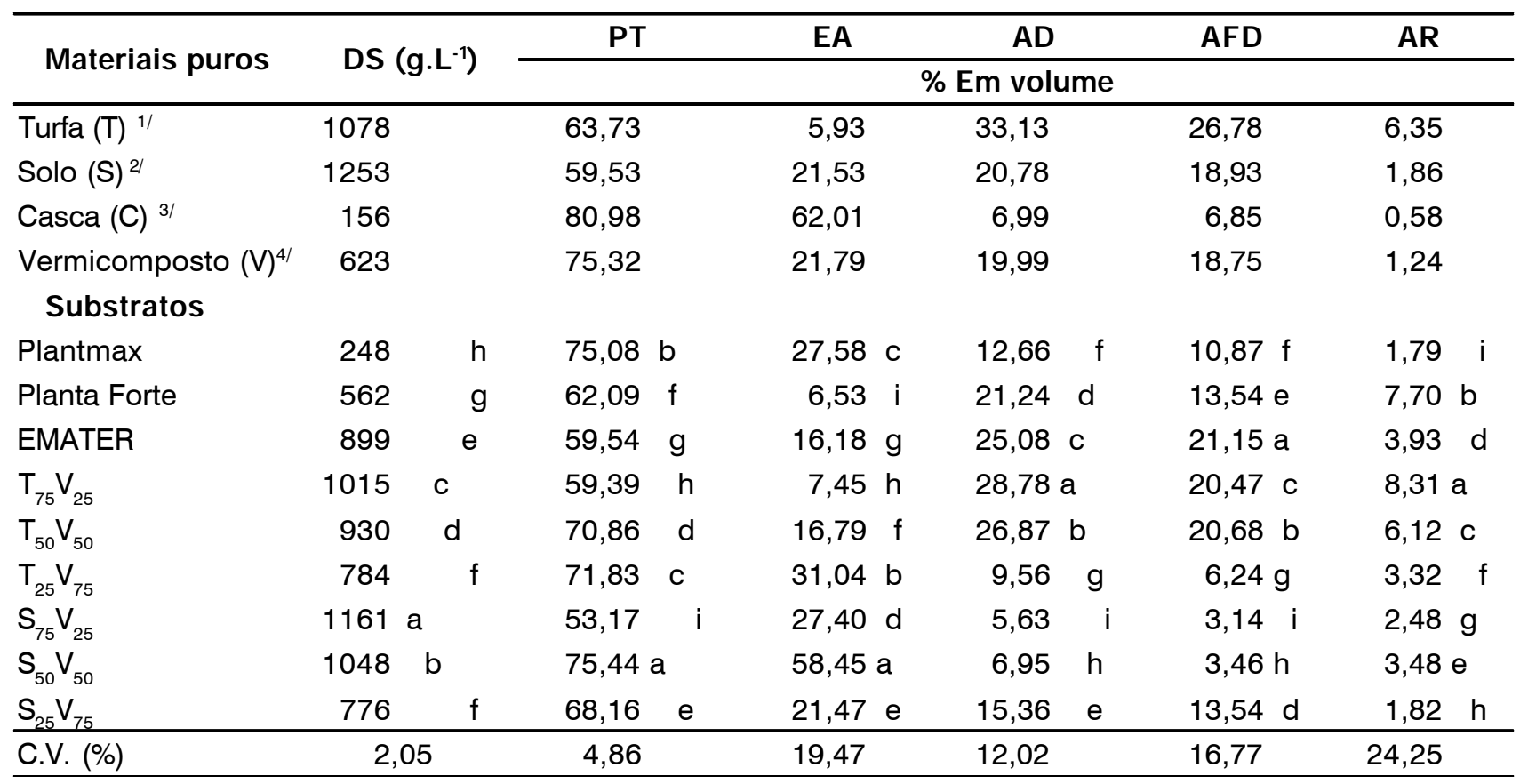

*/ Médias seguidas da mesma letra nas colunas não diferem entre si a $5 \%$ de probabilidade pelo teste de Duncan;

1/ Turfa "Petrolini"; ${ }^{2 /}$ solo PVA; 3 / casca de arroz carbonizada; 4 / vermicomposto.

Tabela 4. Distribuição do tamanho de partículas $(\mathrm{mm})$ dos materiais puros, substratos comerciais e formulados em estudo para a formação de mudas de alface. Pelotas, UFPel, 1998.

\begin{tabular}{|c|c|c|c|c|c|c|c|c|}
\hline Materiais puros & $>4,75$ & $\begin{array}{c}2,00- \\
4,75\end{array}$ & $\begin{array}{c}1,00- \\
2,00\end{array}$ & $\begin{array}{c}0,71- \\
1,00\end{array}$ & $\begin{array}{c}0,59- \\
0,71\end{array}$ & $\begin{array}{c}0,25- \\
0,59\end{array}$ & $0,106-0,250$ & $\begin{array}{c}0,001- \\
0,106\end{array}$ \\
\hline Turfa $^{1 /}$ & 0,0 & 4,6 & 9,1 & 4,5 & 3,4 & 23,4 & 48,3 & 6,7 \\
\hline Solo $2 /$ & 0,0 & 17,4 & 22,3 & 11,2 & 8,0 & 25,9 & 11,0 & 4,2 \\
\hline Casca $^{3 /}$ & 0,4 & 25,5 & 28,9 & 17,2 & 8,5 & 15,4 & 2,9 & 1,4 \\
\hline Vermicomposto ${ }^{4 /}$ & 1,0 & 17,8 & 21,7 & 14,7 & 10,0 & 24,1 & 7,9 & 2,7 \\
\hline \multicolumn{9}{|l|}{ Substratos } \\
\hline Plantmax & 2,7 & 15,8 & 14,6 & 7,4 & 4,8 & 13,6 & 6,7 & 34,3 \\
\hline Planta Forte & 5,7 & 18,0 & 12,6 & 5,9 & 3,9 & 15,5 & 13,5 & 24,9 \\
\hline EMATER & 0,0 & 12,1 & 15,6 & 8,6 & 5,5 & 21,3 & $30,7 \quad c$ & 6,2 \\
\hline $\mathrm{T}_{75} \mathrm{~V}_{25}$ & 0,2 & 6,0 & 10,7 & 5,6 & 3,6 & 19,3 & $45,3 \mathrm{a}$ & 9,2 \\
\hline $\mathrm{T}_{50} \mathrm{~V}_{50}$ & 0,2 & 5,3 & 9,6 & 6,4 & 3,7 & 20,8 & $41,0 \quad b$ & 13,0 \\
\hline $\mathrm{T}_{25} \mathrm{~V}_{75}$ & 0,4 & 7,7 & 12,2 & 8,2 & 6,0 & 22,7 & $27,1 \quad d$ & 12,8 \\
\hline$S_{75} V_{25}$ & 0,0 & 11,1 & 18,9 & 11,7 & 8,5 & 28,9 & 15,6 & 5,2 \\
\hline$S_{50} V_{50}$ & 0,2 & 15,6 & 20,1 & 10,4 & 6,6 & 24,5 & 11,4 & 11,1 \\
\hline $\mathrm{S}_{25} \mathrm{~V}_{75}$ & 0,2 & 13,0 & 17,8 & 11,4 & 9,2 & 24,6 & 10,3 & 12,6 \\
\hline
\end{tabular}

*/ Médias seguidas da mesma letra nas colunas não diferem entre si a 5\% de probabilidade pelo teste de Duncan;

1/ Turfa "Petrolini"; ${ }^{2 /}$ solo PVA; ${ }^{3 /}$ casca de arroz carbonizada; ${ }^{4 /}$ vermicomposto.

devido a uma pressão osmótica do meio (solução do substrato) maior que a do suco celular o que pode levar à desidratação destas, dano permanente e até a morte das plantas.
Os substratos testemunhas (EMATER, Plantmax e Planta Forte), proporcionaram o menor desenvolvimento das plântulas em comparação àqueles formulados com vermicom- posto devido a características próprias de cada material. O substrato EMATER apresentou a mais baixa concentração de sais de todos os tratamentos, $\mathrm{pH}$ inferior ao recomendado à espécie, o que 
associado a baixa capacidade de troca de cátions culminou em menor disponibilidade de nutrientes e por conseqüência em menor número de folhas definitivas e pesos de matéria seca (Tabelas 1 e 2). O mesmo efeito sobre o desenvolvimento vegetativo das plântulas foi observado para os substratos comerciais Plantmax e Planta Forte, contudo por diferentes causas. Em relação ao substrato Plantmax, o alto teor total de sais solúveis inicialmente registrado prejudicou o estabelecimento das plântulas, ao aumentar o tempo de emergência e dificultar o desenvolvimento radicular. O menor vigor das raízes, observado posteriormente, pode ser explicado pela alta porosidade do substrato, a qual dificultou o armazenamento de água, proporcionando uma alta lixiviação de nutrientes (Tabelas 1 e 3 ). Adite-se a isso o baixo $\mathrm{pH}$ observado para o material $(5,07)$, o qual diminuiu a disponibilidade de nutrientes durante o desenvolvimento das plântulas. Para o substrato Planta Forte, o menor desenvolvimento vegetativo está relacionado ao alto teor total de sais solúveis e ao elevado $\mathrm{pH}$ $(7,00)$, dificultando o estabelecimento inicial das plântulas e, posteriormente, reduzindo a disponibilidade de nutrientes durante o desenvolvimento das mesmas.

Todos os substratos formulados com vermicomposto proporcionaram melhor desenvolvimento vegetativo das plântulas quando comparados às testemunhas (substratos comerciais e EMATER), o que se deve a melhores combinações entre suas propriedades físicas e químicas, destacam-se entre eles os tratamentos $\mathrm{T}_{50} \mathrm{~V}_{50}, \mathrm{~S}_{75} \mathrm{~V}_{25}$, $\mathrm{S}_{50} \mathrm{~V}_{50}$, e $\mathrm{S}_{25} \mathrm{~V}_{75}$. Na Tabela 2, pode-se verificar que estes substratos apresentaram um valor de $\mathrm{pH}$ adequado ao desenvolvimento da espécie, o qual segundo a Comissão de Fertilidade do Solo RS/SC (1995), deve ser de 6,0. Embora alguns substratos tenham proporcionado maior tempo de emergência, devido aos elevados teores salinos iniciais, a lixiviação dos sais destes substratos, proporcionada pela irrigação, somada a uma melhor relação concentração salina:teor de água no substrato, minimizou o efeito danoso observado inicialmente, refletindo-se em melhor desenvolvimento radicular, o qual juntamente com potenciais hidrogenionicos, CTC e teores de matéria orgânica adequados, propiciaram uma melhor absorção de nutrientes, culminando em maior número de folhas definitivas e pesos de matéria seca (Tabelas 2 e 3). A comparação entre materiais com características diversas deve ser feita com cautela, estando relacionada a um conjunto de fatores intrínsecos de cada material. Assim, pode-se observar pelos resultados que substratos com diferentes composições e propriedades, como os substratos $\mathrm{T}_{50} \mathrm{~V}_{50}$ e $\mathrm{S}_{75} \mathrm{~V}_{25}$, podem da mesma forma proporcionar um bom desenvolvimento vegetativo das plântulas. Contudo, a escolha de uma ou outra formulação, deve estar relacionada, além de fatores técnicos e aspectos de uso, ao custo e disponibilidade dos materiais a longo prazo (Lorenzo \& Sant, 1981; Bellé, 1990; Grolli, 1991). Em relação ao último aspecto, o uso da turfa como substrato tem sido ecológicamente questionado (Chong \& Rinker, 1994), uma vez que além de não ser um material renovável a curto prazo, exige custos adicionais de remoção e transporte. Optou-se, portanto, em se comparar o custo de produção dos melhores substratos formulados com solo e vermicomposto ao preço dos substratos comerciais praticados no comércio local.

Segundo dados da Cooperativa de Minhocultores Sul-riograndense (COOMESUL), o custo médio de um quilo de vermicomposto na propriedade, mesmo que o produtor tenha que adquirir a matéria prima (esterco bovino) de terceiros é de R $\$ 0,10$. Os custos de fumigação dos substratos, por sua vez, irão variar de acordo com as densidades secas dos materiais puros, assim como das proporções em volume em que os mesmos serão utilizados. Para a fumigação foi utilizado o brometo de metila na dosagem $131 \mathrm{~cm} 3 \cdot \mathrm{m}^{-3}$ de substrato (ANDREI, 1996), equivalente a uma lata de $680 \mathrm{~g}$, cujo preço no comércio local é de $\mathrm{R} \$ 7,50$.

Assim, o custo total da produção dos substratos formulados com "solo" e vermicomposto são muito inferiores aos comerciais, enquanto para a formulação de $25 \mathrm{Kg}$ do substrato $\mathrm{S}_{75} \mathrm{~V}_{25}$, são ne- cessários $\mathrm{R} \$ 0,42$, o produtor para adquirir a mesma quantidade do substrato Plantmax teria que desembolsar a quantia de $\mathrm{R} \$ 7,80$. Portanto, torna-se possível e vantajosa a formulação de substratos que garantam um bom desenvolvimento vegetativo das plântulas até a fase de muda na própria propriedade.

\section{LITERATURA CITADA}

ANDREI, E. Compêndio de defensivos agrícolas. 5a ed. São Paulo: Andrei Editora Ltda., 1996. $506 \mathrm{p}$.

BACKES, M.A.; KÄMPF, A.N.; BORDAS J.M.C. Substratos para a produção de plantas em viveiros. In: CONGRESSO FLORESTAL ESTADUAL, 1988, Nova Prata. Anais... Nova Prata, Secretaria da Agricultura do Rio Grande do Sul/Prefeitura Nova Prata, 1988. p. 665675.

BELLÉ, S. Uso da turfa "Lagoa dos Patos" (Viamão/RS) como substrato hortícola. Porto Alegre: UFRGS, 1990. 142 p. (Tese mestrado).

BILDERBACK, T.E.; FONTENO, W.C.; JOHSON, D.R. Physical properties of media composed of peanut hulls, pine bark and peatmoss and their effects on azalea growth. Journal of the American Society for Horticultural Science, v. 107, n. 3, p. 522 525, 1982.

BORDAS, J.M.C.; BACKES, M.A.; KÄMPF, A.N. Características físicas e químicas de substratos comerciais. In: CONGRESSO FLORESTAL ESTADUAL, 1988, Nova Prata. Anais... Nova Prata: Secretaria da Agricultura do Rio Grande do Sul/Prefeitura Nova Prata ,1988. p. 427 - 435.

CARMELLO, Q.A.C. Nutrição e adubação de mudas hortícolas. In: MINAMI, K. Produção de mudas de alta qualidade em horticultura. São Paulo: T.A. Queiroz, 1995. p. 27 - 37.

CARNEIRO, J.G.A. Produção e controle de qualidade de mudas florestais. Curitiba: UFPR/ FUPEF, 1995. $451 \mathrm{p}$.

CHONG, C.; RINKER, D.L. Use of spent mushroom substrate for growing containerized woody ornamentals: An overview. Compost Science \& Utilization, v. 2, n. 3, p. 45-53, 1994.

COMISSÃO DE FERTILIDADE DO SOLO - RS/ $\mathrm{SC}$ Recomendações de adubação e de calagem para os estados do Rio Grande do Sul e Santa Catarina. 3a ed. Passo Fundo: SBCS - Núcleo Regional Sul, 1995. 224 p.

DE BOODT, M. The floricultural centre of Ghent as modelled by its substrata. Acta Horticulturae, v. 37, p. 1909 - 1917, 1974.

DE BOODT, M.; VERDONCK, O. The physical properties of the substrates in horticulture. Acta Horticulturae, v. 26, p. 37 - 44, 1972.

EMATER. Substrato para a produção de mudas. Recomendações Técnicas, Camaquã, RS. s.d.

GIORGETTI, J.R. Produção e comercialização de mudas de tomate. In: ENCONTRO NACIONAL DE PRODUÇÃO E ABASTECIMENTO DE TOMATE, 2. 1991, Jaboticabal, São Paulo. Anais... Jaboticabal: UNESP, 1991. p. $242-244$. 
GRAZIANO, T.T.; DEMATTÊ, J.B.I.; VOLPR, C.A.; PERECIN, D. Interação entre substratos e fertirrigação na germinação e na produção de mudas de Tagedes patula L. (Compositae). Revista Brasileira de Horticultura Ornamental, Campinas, v. 1, n. 2, p. 78 - 85, 1995.

GROLLI, P.R. Composto de lixo domiciliar urbano como condicionador de substratos para plantas arbóreas. Porto Alegre: UFRGS, 1991. 114 p. (Tese mestrado).

HANDRECK, K.A. Particle size and the physical properties of growing media for containers. Communication in Soil Science and Plant Analysis, v. 14, n. 3, p. 209 - 222, 1983.

HOFFMANN, G. Verbindliche Methoden zur Untersuchung von tks und gärtnerischen Erden. Mitteilungen der VDLUFA, v. 6, p. 129153, 1970.

JUNGK, A. Eigenschaften des Torfs und anderer Substrate in ihrer Bedeutung für die Ernährung der Pflanze. Telma, v. 5, p. 167 - 187, 1975.

KIEHL, E.J. Manual de Edafologia: Relações Solo-Planta. São Paulo: Editora Agronômica Ceres Ltda, 1979. 262 p.

LAMAIRE, F. Physical, chemical and biological properties of growing medium. Acta Horticulturae. v. 396, p. 273-284, 1995.

LORENZO, P.; SANT, M.D. Effects of physical media properties on Codiaeum variegatum rooting response. Acta Horticulturae, v. 126, p. $293-302,1981$.

MALAVOLTA, E. Manual de Química Agrícola: Adubos e Adubação. 3a ed. .São Paulo: Editora Agronômica Ceres Ltda, 1981. p. 80.
MELE, E.; MATALlANA, A.; PAGES, M.; TRILLAS, M.; ISABEL, M. Influencia de las propriedades físicas del substrato en horticultura ornamental. Aplicacion al Pelargonium zonale. Anales del Instituto Nacional de Investigaciones Agrarias. Série Agrícola, v. 18, p. 57 - 64, 1982.

MENEZES JÚNIOR, F.O.G. Caracterização de diferentes substratos e seu efeito na produção de mudas de alface e couve-flor em ambiente protegido. Pelotas: UFPel, 1998. 142 p. (Tese mestrado).

MINAMI, K. Produção de Mudas de Hortaliças de Alta Qualidade em Horticultura. São Paulo: T.A. Queiroz, 1995, 128 p.

PENNINGSFELD, F. Substrates for protected cropping. Acta Horticulturae, v. 82, p. 13 - 22, 1978.

PENNINGSFELD, F. Kultur Substrate für den Gartenbau, besonders in Deutschland: Ein kritischer Überblick. Plant and Soil, v. 75, p. 269 - 281, 1983.

PRASAD, M. Physical properties of media for container-grown crops. New Zealand peats and wood wastes. Scientia Horticulturae, v. 10, p. 317 - 323, 1979a.

PRASAD, M. Physical properties of media for container-grown crops. New Zealand peats and wood wastes. Scientia Horticulturae, v. 10, p. $325-330,1979 b$.

SANCHO, J.F.A. The present status of the substrate as an ecosystem component and its function and importance in crop productivity. Acta Horticulturae, v. 221, p. 53 - 74, 1988.
SILVA JÚNIOR, A.A.; VISCONTI, A. Recipientes e substratos para a produção de mudas de tomate. Agropecuária Catarinense, Florianópolis, v. 4, n. 4, p. 20 - 23, 1991.

SILVA JÚNIOR, A.A.; MACEDO, S.G.; STUKER, H Utilização de esterco de perú na produção de mudas de tomateiro. Florianópolis : EPAGRI, 1995. 28 p. (Boletim Técnico, 73).

SOUZA, M.M.; LOPES, L.C.; FONTES, L.E.F. Avaliação de substratos para o cultivo de crisântemo (Chrysanthemum morifolium Ramat. Compositae) "White Polaris" em vasos. Revista Brasileira de Horticultura Ornamental, Campinas, v. 1, n. 2, p. 71 - 77, 1995.

TEDESCO, M.J.; VOLWEIS, S.J.; BOHNEN, H Análises de solos, plantas e outros materiais. Porto Alegre: Departamento de Solos da Faculdade de Agronomia da UFRGS, 1985. 188 p. (Boletim Técnico, 5).

VERDONCK, O.; DE VLEESCHAUWER, D.; DE BOODT, M. The influence of the substrates to plant growth. Acta Horticulturae, v. 126 , p. $251-258,1981$.

VERDONCK, O. Reviewing and evaluation of new materials used as substrates. Acta Horticulturae, v. 150, p. 467 - 473, 1983.

WALLER, P.L.; WILSON, F.N. Evaluation of growing media for consumer use. Acta Horticulturae, v. 150, p. 51 - 57, 1983. 